\title{
Assessment of knowledge, attitude, and practice related to epilepsy: a community- based study
}

This article was published in the following Dove Press journal:

Neuropsychiatric Disease and Treatment

21 May 2015

Number of times this article has been viewed

\author{
Jalle Teferi' \\ Zewdu Shewangizaw ${ }^{2}$ \\ 'Addis Ababa Health Bureau, \\ Zewuditu Specialized Hospital, Addis \\ Ababa, Ethiopia; ${ }^{2}$ College of Medicine \\ and Health Sciences, Arba Minch \\ University, Arba Minch, Ethiopia
}

\begin{abstract}
Religious and sociocultural beliefs influence the nature of treatment and care received by people with epilepsy. Many communities in Africa and other developing nations believe that epilepsy results from evil spirits, and thus, treatment should be through the use of herbaceous plants from traditional doctors and religious leadership. Community-based crosssectional study designs were used to assess the knowledge, attitude, and practice related to epilepsy and its associated factors by using a pretested, semi-structured questionnaire among 660 respondents living in Sululta Woreda, Oromia, Ethiopia. According to the results of this study, $59.8 \%$ of the respondents possessed knowledge about epilepsy, $35.6 \%$ had a favorable attitude, and $33.5 \%$ of them adopted safe practices related to epilepsy. The following factors had significant association to knowledge, attitude, and practice related to epilepsy: being rural dwellers, living alone, those with more years of formal education, heard information about epilepsy, distance of health facility from the community, had witnessed an epileptic seizure, age range from 46 years to 55 years, had heard about epilepsy, prior knowledge of epilepsy, occupational history of being self-employed or a laborer, history of epilepsy, and history of epilepsy in family member. The findings indicated that the Sululta community is familiar with epilepsy, has an unfavorable attitude toward epilepsy, and unsafe practices related to epilepsy, but has a relatively promising knowledge of epilepsy.
\end{abstract}

Keywords: Oromia, favorable attitude, safe practice, rural

\section{Introduction}

Epilepsy is a neurological condition characterized by recurrent seizures. A seizure is a transient disturbance of the cerebral function secondary to abnormal paroxysms in the brain, which results in a sudden excessive disorderly discharge of the cerebral neurons. The discharge results in an almost instantaneous disturbance of sensation, loss of consciousness or psychic function, convulsive movements, or combinations of these. ${ }^{1,2}$ Persons with epilepsy are at a risk of developing a variety of psychological problems, including depression and anxiety, and psychosis. ${ }^{3}$ Previous studies show that the prevalence of active epilepsy in developing countries range from 5 to 10 per 1,000 people. ${ }^{4}$ However, the worldwide prevalence rate of epilepsy varies from 2.8 to 19.5 per 1,000 of the general population and is more prevalent among children. ${ }^{5}$ In Nigeria, the estimated prevalence of epilepsy is $8-13$ per 1,000 people. ${ }^{6}$ In developing countries, the disorder is to a significant degree associated with a host of parasitic and bacterial infectious diseases that are largely absent in industrialized countries. ${ }^{7}$

Sociocultural attitudes continue to cause a negative impact on the management of epilepsy in many African nations. ${ }^{8}$ The disorder is enrobed in superstition,
Correspondence: Zewdu Shewangizaw College of Medicine and Health Sciences, Arba Minch University, PO Box 21,

Arba Minch, Ethiopia

Tel +25I 913749690

Email hweret@gmail.com 
discrimination, and stigma in many of these states. ${ }^{9}$ Religious and sociocultural beliefs influence the nature of treatment and maintenance received by people with epilepsy. Many communities in Africa and other developing countries believe that epilepsy results from witchcraft or possession by evil spirits, and hence, treatment should be through the use of herbs from traditional doctors, fetish priests, and religious leaders. ${ }^{9}$ Persons with epilepsy are shunned and discriminated against in education, employment, and marriage in Africa because epilepsy is seen as a highly contagious and shameful disease in the eyes of the public. ${ }^{10}$

Study findings from Ghana indicated that $45.3 \%$ of study participants did not know the cause of epilepsy; besides, $37.6 \%$ of the participants did not know how to treat a patient with epilepsy. The study also shows that youngsters who have lower educational levels and single marital status did not have good knowledge of epilepsy. ${ }^{6}$

A study conducted in Butajira regarding the attitude and practice of people related to mental disorders has shown that $41 \%$ of the informants preferred modern medicine for neuropsychiatry disorders. ${ }^{11}$ Moreover, study results from rural community in Jimma, Ethiopia on the knowledge, attitude, and practice (KAP) related to epilepsy reveal that poor knowledge as well as inappropriate attitude and practice were observed in the community. ${ }^{12}$

With several limitations, studies show that misconception, superstition, ignorance, and prejudice are still evident and contribute to the low levels of conventional epilepsy care and the treatment gap. ${ }^{10}$

Though studies were conducted on KAP related to epilepsy in various African countries, KAP related to epilepsy has not yet adequately been studied at a community level in Ethiopia.

Hence, this study tries to assess KAP and its associated factors related to epilepsy in Sululta Woreda, Oromia, Ethiopia. This study aims to help improve the utilization of primary mental health services by bridging the treatment gap between the communities and health facilities.

\section{Methods}

Community-based cross-sectional study with the multistage sampling technique was conducted in Oromia Regional State, Sululta Woreda, Ethiopia. The people belonging to the Sululta community from all households were taken as source population. Individuals of age over 18 years (357 males and 303 females) with sound mental health were selected as the study population. The sample size was calculated using single population proportion formula to estimate the study sample by using margin of error 0.05 and proportion of event occurrence at $28 \%$ similar to studies conducted at Northern Nigeria ${ }^{13}$ at $95 \%$ of level of significance by adding a $10 \%$ nonrespondent rate. Based on the above assumption, the minimum sample size required for the study was 618 .

Data were collected through interviews by using previously adopted standard questionnaire that was translated into local languages. In addition to providing a translation, the data quality was assured by daily checking to control the quality of data collected from the study subject by supervisors. Data analysis was performed using SPSS statistical software. Sociodemographic data and the levels of KAP of the study participants related to epilepsy were measured by the number of occurrences (ie, frequencies) for descriptive variables and binary logistic regression was undertaken to explore the factors associated with adherence $(P<0.05)$ to provide the odds ratio (OR) at $95 \%$ confidence interval (CI). Bivariate association between dependent and independent variables was determined and covariates with $P>0.2$ with the outcome variable were dropped from further consideration in modeling by using multivariate analysis as an adjusted OR (AOR). According to the current study, "good knowledge" is defined as when respondents scored $\geq 50 \%$ when answering questions related to epilepsy knowledge and "poor knowledge" is defined as when respondents scored $<50 \%$. The attitude of participants was defined as "favorable" for a score $\geq 50 \%$ and as "unfavorable" for a score $<50 \%$. Similarly, the study defines practice in epilepsy as "safe" for respondents who scored $\geq 50 \%$, and as "unsafe" for those who scored $<50 \%$.

Ethical clearance was obtained from Oromia Regional Health Bureau Research and Publication Committee (DRPC). Further, permission was obtained from Oromia, Finfine Special Zone, and Woreda Health Office.

\section{Results}

\section{Sociodemographic characteristics}

Of the 682 study participants, 660 completed the study with a $96.8 \%$ response rate. The median age of the respondents was 30 years and the range was $18-55$ years. A majority of the study participants $(94.4 \%)$ were of Oromo ethnicity, and half (48.1\%) of them were women; $26.1 \%$ of them were single girls. Regarding educational status, $55.4 \%$ of the participants had completed primary education. Regarding family role, $35.5 \%$ of the participants were family heads. By residency, $72 \%$ of the participants were rural dwellers as shown by Table 1 . 
Regarding prior source of information about epilepsy, $63.4 \%$ of the participants had the information from mass media (TV/radio), whereas $22.1 \%, 12.6 \%$, and $1.9 \%$ of the study subjects had the information from health facilities, health extension workers, and school, respectively.

\section{KAP related to epilepsy}

According to the study, 59.8\%, 35.6\%, and 33.5\% of respondents had good knowledge, favorable attitude, and safe practice related to epilepsy, respectively, as shown in Figure 1.

\section{Factors associated with KAP of epilepsy}

Bivariate logistic regression was conducted to assess the association between the outcome variables and others variables of

Table I Sociodemographic characteristics of participants in the epilepsy study from the Sululta Woreda community in Oromia, Ethiopia

\begin{tabular}{lll}
\hline Variables & Number & Percentage \\
\hline Area type & & \\
Rural & 503 & 76.2 \\
Urban & 157 & 23.8 \\
Sex & & \\
Male & 357 & 54.1 \\
Female & 303 & 45.9 \\
Age & & \\
I8-35 years & 445 & 67.4 \\
36-45 years & 151 & 22.9 \\
46-55 years & 64 & 9.7 \\
Ethnicity & & \\
Oromo & 623 & 94.4 \\
Others & 37 & 5.6 \\
Family role & & \\
Father & 292 & 44.2 \\
Mother & 234 & 35.5 \\
Son & 104 & 15.8 \\
Ground father & 2 & 0.3 \\
Living alone & 28 & 4.2 \\
Religion & & \\
Orthodox Christianity & 642 & 97.3 \\
Catholic & 6 & 0.9 \\
Protestant & 9 & 1.4 \\
Muslim & 3 & 0.5 \\
Educational status & & \\
Literate & 294 & 12.6 \\
Primary school & 233 & 2.5 \\
High school & 82 & \\
College & 36 & \\
Professional & 15 & \\
Occupation & & \\
Unemployed & 54.6 \\
Employed & & \\
Laborer & & \\
Farmer & & \\
\hline
\end{tabular}

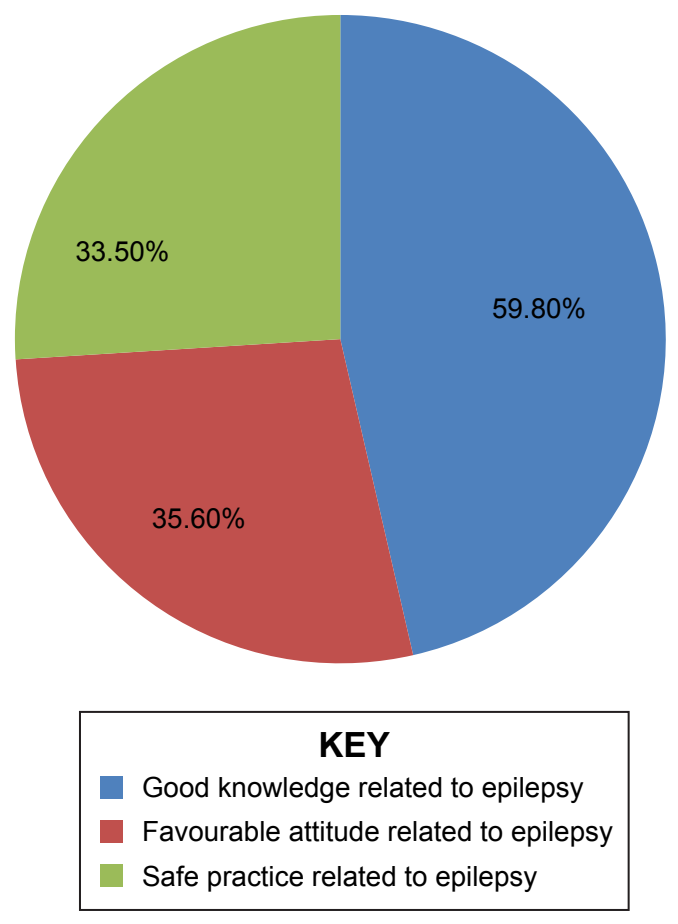

Figure I Prevalence in study participants of good knowledge, favorable attitude, and safe practice related to epilepsy in Sululta Woreda, Oromia, Ethiopia.

epilepsy. Data collected show that the following factors had been associated with knowledge of epilepsy: respondents' sex, family role, educational status, whether they lived in a rural or urban area, had heard about epilepsy, knew someone with epilepsy, had witnessed a seizure, or had epileptic family members.

The following factors were found to be significantly associated with the attitude about epilepsy in bivariate analysis: respondent's age, family role, educational status, occupation, whether they had heard about epilepsy, where they heard about epilepsy, whether they knew someone with epilepsy, and the distance of their home from a health institution. Likewise, in bivariate analysis, the following factors were shown to be associated with the practice related to epilepsy: respondents' sex, age, family role, educational status, occupation, distance of home from health institution, whether they had heard about epilepsy, knew someone with epilepsy, had witnessed a seizure, or had epileptic family members.

Multivariate analysis shows that rural dwellers (AOR $=0.58,95 \% \mathrm{CI}=0.35-0.96)$ and participants living alone (AOR $=0.36,95 \% \mathrm{CI}=0.14-0.9)$ were less knowledgeable about epilepsy. There was a significant association between knowledge of epilepsy and the distance between the respondents home and health institutions: respondents who lived short distances from health institutions (31-60 minutes 
walking time) were likely to be more knowledgeable (AOR 95\% CI, 0.47 [0.27, 0.83]); whereas respondents who lived further away from health institutions (more than 61 minutes walking time) were likely to be less knowledgeable. Respondents with a higher educational status, for instance, secondary level (AOR 95\% CI, 2.30 [1.18, 4.480]) and college level (AOR 95\% CI, 2.43 [1.03, 5.73]), have positive association with the level of knowledge about epilepsy. The results of this study showed that participants who had heard about epilepsy (AOR 95\% CI, 0.13 [0.06, 0.27]) and knew someone who has epilepsy (AOR 95\% CI, 0.57 [0.35, 0.92]) were more knowledgeable than those who had not heard and known (Table 2).

Regarding factors associated with attitude toward epilepsy, residency being rural (AOR 95\% CI, 0.12 [0.07, 0.22]), had less attitude toward epilepsy, age group when $\geq 46$ years (AOR 95\% CI, $2.05[1.04,4.04])$ had positive attitude than age group with early adolescence.

There was significant association between educational status and attitude about epilepsy. Respondents with secondary and college levels of education had a favorable attitude about epilepsy compared with those who were illiterate: secondary education (AOR 95\% CI, 3.89 [1.87,8.07]); and college education (AOR 95\% CI, 6.98 [2.67;18.31]). Further, those who lived in an urban area (AOR 95\% CI, 0.12 [0.07, 0.22]) were more likely to have had a positive attitude about epilepsy than those who lived in a rural area. Moreover, respondents in the age group from 46 years to 55 years $(\mathrm{AOR}=2.05,95 \%$ $\mathrm{CI}=1.04-4.04$ ) had positive attitude compared to those in the younger age group.

Table 2 Association of selected sociodemographic and related factors for knowledge related to epilepsy among the study participants, in Sululta Woreda, Oromia, Ethiopia

\begin{tabular}{|c|c|c|c|c|}
\hline \multirow[t]{2}{*}{ Variable } & \multicolumn{2}{|c|}{ Level of knowledge, $n$} & \multirow[t]{2}{*}{ COR $(95 \% \mathrm{CI})$} & \multirow[t]{2}{*}{ AOR $(95 \% \mathrm{Cl})$} \\
\hline & Good & Poor & & \\
\hline \multicolumn{5}{|l|}{ Sex } \\
\hline Female & 165 & 139 & 1 & 1 \\
\hline Male & 230 & 126 & $1.54(1.12,2.10)^{*}$ & $\mathrm{I} .4 \mathrm{I}(0.8 \mathrm{I}, 2.43)$ \\
\hline \multicolumn{5}{|l|}{ Area type } \\
\hline Urban & 110 & 47 & I & I \\
\hline Rural & 285 & 218 & $0.56(0.38,0.82)^{*}$ & $0.58(0.35,0.96)^{*}$ \\
\hline \multicolumn{5}{|l|}{ Family role } \\
\hline Husband & 188 & 104 & I & 1 \\
\hline Mother & 128 & 106 & $0.67(0.47,0.95)^{*}$ & $1.25(0.68,2.30)$ \\
\hline Son/daughter & 65 & 39 & $0.92(0.58,1.47)$ & $1.13(0.63,2.02)$ \\
\hline Grandparent/mom/dad & I & I & $0.55(0.03,8.94)$ & $0.33(0.02,5.75)$ \\
\hline Living alone & 13 & 15 & $0.48(0.22,1.05)$ & $0.36(0.14,0.90)$ \\
\hline \multicolumn{5}{|l|}{ Education } \\
\hline Illiterate & 142 & 152 & 1 & I \\
\hline Primary school & 156 & 77 & $2.17(1.52,3.10)^{*}$ & I.46 $(0.95,2.23)$ \\
\hline Secondary & 58 & 24 & $2.59(1.53,6.00)^{*}$ & $2.30(1.18,4.48)^{*}$ \\
\hline College & 39 & 12 & $3.48(1.75,6.91)^{*}$ & $2.43(1.03,5.73)^{*}$ \\
\hline \multicolumn{5}{|l|}{ Had heard about epilepsy } \\
\hline No & 383 & 196 & I & 1 \\
\hline Yes & 12 & 69 & $0.39(0.24,0.63)^{*}$ & $0.13(0.06,0.27)^{*}$ \\
\hline \multicolumn{5}{|c|}{ Walking time between home and health institution } \\
\hline$<30$ minutes & 260 & 154 & I & I \\
\hline $31-60$ minutes & 33 & 50 & $0.99(0.68,1.44)$ & $0.47(0.27,0.83)^{*}$ \\
\hline$>61$ minutes & 102 & 61 & $0.29(0.21,1.00)$ & $1.74(1.08,2.82)^{*}$ \\
\hline \multicolumn{5}{|c|}{ Knew someone with epilepsy } \\
\hline No & 282 & 112 & I & I \\
\hline Yes & 113 & 153 & $0.29(0.2 \mathrm{I}, 0.4 \mathrm{I})^{*}$ & $0.57(0.35,0.92)^{*}$ \\
\hline \multicolumn{5}{|l|}{ Had witnessed a seizure } \\
\hline No & 106 & 135 & I & I \\
\hline Yes & 289 & 130 & $2.83(2.04,3.93)^{*}$ & $1.18(0.72,1.94)$ \\
\hline \multicolumn{5}{|c|}{ Had a family member with epilepsy } \\
\hline No & 339 & 242 & I & I \\
\hline Yes & 56 & 23 & $1.74(1.04,2.91)^{*}$ & $1.36(0.76,2.45)$ \\
\hline
\end{tabular}

Note: $* P$-value $<0.2$.

Abbreviations: $\mathrm{COR}$, crude odds ratio; $\mathrm{AOR}$, adjusted odds ratio; $\mathrm{Cl}$, confidence interval. 
Respondents who had heard information about epilepsy had positive attitude (AOR 95\% CI, 5.8 [1.26-26.81]), compared with those who had not had information about epilepsy. Meanwhile, respondents who knew someone with epilepsy were positively associated with attitude toward epilepsy (AOR 95\% CI, $0.42[0.26,0.67]$ ) than those who did not know someone who has epilepsy as shown in Table 3.

According to the result of the study, with respect to the practice of the community related to the management of epilepsy, respondents in the age group ranging from 46-55 years (AOR 95\% CI, $2.41[1.21,4.77])$ had an association with safe practice in the management of epilepsy.

Additionally, tertiary level of educational background (AOR 95\% CI, 0.15 [0.05, 0.45]), and individuals who had occupational history in labor and business areas, had a positive association with safe practice in management of epilepsy.

Having prior information about epilepsy (AOR 95\% CI, $0.27[0.10,0.690])$ had a positive association with safe practice of epilepsy management. Having previous exposure/knowing epileptic patients, previous experience in the management of epilepsy, epilepsy in a family member, and safely managing epilepsy would be associated related to safe practice in epilepsy (Table 4).

\section{Discussion}

In Ethiopia, a few studies do suggest that epilepsy is a major problem within the country. ${ }^{14}$ This study tries to assess KAP of epilepsy and associated factors of epilepsy among Sululta Woreda in Oromia, Ethiopia. According to the result of this study, approximately $59.8 \%$ of respondents were knowledgeable, $35.6 \%$ had favorable attitude, and $33.5 \%$ had safe practice toward epilepsy, respectively. This study shows less level of knowledge while it compares with studies conducted in Karachi, Pakistan (77.5\%). ${ }^{15}$

Moreover, our current study shows less improvement in knowledge of epilepsy compared with studies carried out among the general public in Ethiopia (89\%), ${ }^{16}$ Italy $(93.4 \%),{ }^{17}$ Cameroon $(100 \%, 99.3 \%),{ }^{18,19}$ Croatia (97\%), ${ }^{20}$ South Korea $(94 \%)^{21}$ and among school teachers in Egypt $(100 \%)^{22}$ and Brazil (100\%). ${ }^{23}$ The difference observed might be arising from differences in the methodologies adopted.

Regarding attitude, the current study shows that 35.6\% of the community have a positive attitude towards epilepsy,

Table 3 Association of selected sociodemographic and related factors to attitude of community related to epilepsy among the study participants in Sululta Woreda, Oromia, Ethiopia

\begin{tabular}{|c|c|c|c|c|}
\hline \multirow[t]{2}{*}{ Variable } & \multicolumn{2}{|c|}{ Attitude toward epilepsy (n) } & \multirow[t]{2}{*}{ COR (95\% CI) } & \multirow[t]{2}{*}{ AOR (95\% CI) } \\
\hline & Unfavorable & Favorable & & \\
\hline \multicolumn{5}{|l|}{ Area type } \\
\hline Urban & 39 & 118 & I & I \\
\hline Rural & 386 & 117 & $0.10(0.07,0.15)^{*}$ & $0.12(0.07,0.22)^{*}$ \\
\hline \multicolumn{5}{|l|}{ Age } \\
\hline $18-35$ years & 273 & 172 & I & 1 \\
\hline $36-45$ years & 115 & 36 & $1.30(1.25,3.10)^{*}$ & $0.78(0.41,1.19)$ \\
\hline $46-55$ years & 37 & 27 & $2.72(0.08,4.00)^{*}$ & $2.05(1.04,4.04)^{*}$ \\
\hline \multicolumn{5}{|l|}{ Education } \\
\hline Illiterate & 229 & 65 & I & 1 \\
\hline Primary & 159 & 74 & $\mathrm{I} .64(\mathrm{I} . \mathrm{II}, 2.42)^{*}$ & $1.58(0.96,2.62)$ \\
\hline Secondary & 28 & 54 & $6.78(3.99$, I I.58)* & $3.89(1.87,8.07)^{*}$ \\
\hline College & 9 & 42 & I6.44 (7.6I, 35.54)* & $6.99(2.67,18.31)^{*}$ \\
\hline \multicolumn{5}{|c|}{ Had heard about epilepsy } \\
\hline No & 364 & 215 & I & I \\
\hline Yes & 61 & 20 & $2.93(0.74$, I I.54) & $5.69(1.23,26.39)^{*}$ \\
\hline \multicolumn{5}{|l|}{ Source of information } \\
\hline Health institution & 67 & 61 & I & I \\
\hline College & 3 & 8 & $0.86(0.48, \mathrm{I} .52)$ & $5.8 \mathrm{I}(\mathrm{I} .26,26.8 \mathrm{I})^{*}$ \\
\hline Mass media & 253 & I |4 & $0.87(0.34,2.00)$ & $0.87(0.5 \mathrm{I}, \mathrm{I} .45)$ \\
\hline HEW* & 41 & 32 & $0.44(0.26,0.75)$ & $0.94(0.45,1.95)$ \\
\hline \multicolumn{5}{|c|}{ Knew someone with epilepsy } \\
\hline No & 227 & 167 & I & 1 \\
\hline Yes & 198 & 68 & $0.47(0.33,0.66)$ & $0.42(0.26,0.67)^{*}$ \\
\hline
\end{tabular}

Note: $* P$-value $<0.2$.

Abbreviations: $\mathrm{COR}$, crude odds ratio; $\mathrm{AOR}$, adjusted odds ratio; $\mathrm{Cl}$, confidence interval; $\mathrm{HEW}$, health extension worker. 
Table 4 Association of selected sociodemographic and related factors to practice of the community toward epilepsy among the study participants, in Sululta Woreda, Oromia, Ethiopia

\begin{tabular}{|c|c|c|c|c|}
\hline \multirow[t]{2}{*}{ Variables } & \multicolumn{2}{|c|}{ Practice related to epilepsy (n) } & \multirow[t]{2}{*}{ COR $(95 \% \mathrm{Cl})$} & \multirow[t]{2}{*}{ AOR $(95 \% \mathrm{Cl})$} \\
\hline & Safe & Unsafe & & \\
\hline \multicolumn{5}{|l|}{ Age } \\
\hline $18-35$ years & 136 & 309 & I & 1 \\
\hline $36-45$ years & 49 & 102 & I.II $(0.74,1.62)$ & $0.68(0.42, \mathrm{I} . \mathrm{II})$ \\
\hline $46-55$ years & 36 & 28 & $2.92(1.71,4.98)^{*}$ & $2.4 \mathrm{I}(\mathrm{I} .2 \mathrm{I}, 4.79)^{*}$ \\
\hline \multicolumn{5}{|l|}{ Education } \\
\hline Illiterate & 105 & 189 & I & I \\
\hline Primary school & 76 & 157 & $0.88(0.60,1.25)$ & $0.75(0.47,1.20)$ \\
\hline Secondary & 35 & 47 & $\mathrm{I} .34(0.8 \mathrm{I}, 2.20)$ & $1.56(0.79,3.09)$ \\
\hline College & 5 & 46 & $1.96(0.75,2.50)$ & $0.15(0.05,0.45)^{*}$ \\
\hline \multicolumn{5}{|l|}{ Occupation } \\
\hline Unemployed & 6 & 26 & I & I \\
\hline Employed & 10 & 44 & $0.99(0.32,3.02)$ & $1.56(0.37,6.59)$ \\
\hline Labor & 34 & 49 & $3(\mathrm{I} . \mathrm{II}, 8.08)^{*}$ & $5.73(1.67,19.69)^{*}$ \\
\hline Business & 30 & 61 & $0.13(2.13,0.79)$ & $4.23(1.24,14.38)^{*}$ \\
\hline Farmer & 141 & 259 & $2.35(0.49,5.86)$ & $2.78(0.9 I, 8.5 I)$ \\
\hline \multicolumn{5}{|c|}{ Had heard about epilepsy } \\
\hline No & 215 & 364 & I & I \\
\hline Yes & 6 & 75 & $0.13(0.05,0.31)^{*}$ & $0.27(0.10,0.69)^{*}$ \\
\hline \multicolumn{5}{|c|}{ Travelling time between home and health institution } \\
\hline$<30$ minutes & 108 & 306 & I & I \\
\hline $31-60$ minutes & 41 & 42 & $2.78(1.70,4.50)^{*}$ & $2.63(1.43,4.84)^{*}$ \\
\hline$>61$ minutes & 72 & 91 & $2.24(1.53,3.27)^{*}$ & $2.62(\mathrm{I} .6 \mathrm{I}, 4.26)^{*}$ \\
\hline \multicolumn{5}{|c|}{ Knew someone with epilepsy } \\
\hline No & 178 & 216 & I & 1 \\
\hline Yes & 43 & 223 & $0.23(0.16,0.34)^{*}$ & $0.5 \mathrm{I}(0.3 \mathrm{I}, 0.90)^{*}$ \\
\hline \multicolumn{5}{|c|}{ Had witnessed a seizure } \\
\hline No & 33 & 208 & I & 1 \\
\hline Yes & 188 & 231 & $5.13(3.39,7.77)^{*}$ & $3.18(1.78,5.65)^{*}$ \\
\hline \multicolumn{5}{|c|}{ Had a family member with epilepsy } \\
\hline No & 171 & 410 & I & I \\
\hline Yes & 50 & 29 & $4.13(2.53,6.75)^{*}$ & $2.26(1.26,4.13)^{*}$ \\
\hline
\end{tabular}

Note: $* P$-value $<0.2$.

Abbreviations: $\mathrm{COR}$, crude odds ratio; $\mathrm{AOR}$, adjusted odds ratio; $\mathrm{Cl}$, confidence interval.

and that there are still negative attitudes towards individuals who suffer from epilepsy. On the other hand, attitudes were more positive compared to that of the participants of a study in Egypt (8\%). ${ }^{24}$ The current study shows less favorable attitude of participants when compared to that of other studies carried out among students in Cameroon (70.6\%, 77.2\%), ${ }^{25,26}$ India $(77.7 \%),{ }^{27}$ and Trinidad and Tobago $(93 \%) .{ }^{28}$ This study finding regarding attitude is similar to the study finding in Vietnam (33\%). ${ }^{29}$ Such differences are often considered to reflect national and cultural attitudes, but it cannot be excluded that cultural differences in willingness to disclose what might be considered a politically incorrect opinion could contribute.

As regards practice related to epilepsy management, this study shows a lower level of practice than studies done in Jimma University Specialized Hospital (53.3\%). ${ }^{30}$ This difference might be due to the methodological differences.
Regarding determinant factors, our current study shows that factors associated with knowledge of epilepsy were, formal secondary education and above, prior information on epilepsy, someone living within 1 hour travel time from the health institution and knowing someone with epilepsy had positively associated with the level of knowledge regarding to epilepsy.

On the other hand, respondents who reside far away from health care institutions, rural dwellers, and those living alone were negatively associated with the level of knowledge about epilepsy. According to the study, variables that affect the outcome variables in the current studies are: being urban dwellers, being in the age group of 46-55 years, having formal education above secondary level, having heard about epilepsy, having obtained information through colleges, and knowing someone with epilepsy. These variables had positive 
association with attitude toward epilepsy. On the contrary, being rural dwellers negatively associated to attitude toward epilepsy.

Studies done in Mekele, Ethiopia showed that factors associated with unfavorable attitude include refusal to marry people with epilepsy (44.8\%), beliefs that epilepsy is caused by evil spirit (33.24\%), is contagious $(28.6 \%)$, or a kind of insanity $(51.6 \%) .{ }^{13}$ Hence, our current study includes other factors that positively and negatively affect but not covered in earlier studies.

Practices related to epilepsy were affected by age greater than 46 years, prior heard information related to epilepsy, being laborers or business men/women, knowing someone with epilepsy, witnessing epilepsy and having a family history of epilepsy had positive association with epilepsy, and distance negatively associated with practices related to epilepsy. On the other hand, a previous study related to epilepsy management showed that nearly $73 \%$ people believed that allopathy is a better option than ayurveda $(25 \%)$. A very small proportion, ie, only $2 \%$ believed that holy treatment with worship is effective in treating epilepsy. Approximately $40 \%$ felt that epilepsy can be cured, but almost $60 \%$ thought that a person with epilepsy has to take lifelong treatment. In response to first aid measures in response to epileptic seizures, $60 \%$ said that they would take the person to a hospital, 23\% felt that they would put a shoe or onion on nose, and $15 \%$ would splash water over the face of the patient. ${ }^{31}$

\section{Conclusion}

The findings indicated that the Sululta community is familiar with epilepsy, yet there is still problem with negative attitude and unsafe practice related to epilepsy; but relatively promising knowledge about epilepsy. Overall, 59.8\% were knowledgeable about epilepsy, $35.6 \%$ had favorable attitude, and $33.5 \%$ of them observed safe practices related to epilepsy.

Living in rural locations, living alone, having education at the secondary or college level, having heard information about epilepsy, distance of health institution from the community, and witnessing epilepsy episodes had significant association to knowledge of epilepsy among respondents.

There was an association for attitute in respondents who lived in a rural area, had secondary or college level education, were aged 46 to 55 years, had heard information about epilepsy, and had prior knowledge of epilepsy being more likely to have a favorable attitude towards epilepsy.

The following factors had a positive association with practices related to epilepsy: study subjects aged 46-55 years, college level of education, occupational history of being self-employed or a laborer, and had heard about epilepsy. Additionally, the following factors had a positive association with epilepsy management: walking distance to health institution $\geq 31$ minutes, knew someone with epilepsy, and had a family member with epilepsy. Hence, we conclude that the current new findings might help initiate further studies because there is still a need for more widespread dissemination of information to improve general knowledge about epilepsy.

\section{Acknowledgments}

The authors acknowledge Sululta Woreda community members and the government office of Oromia Regional Health Bureau for their support for the study.

\section{Author contributions}

JT worked on the draft of the full document and ZS worked on rewriting, editing, and formatting of the document. Both authors contributed toward data analysis, drafting, and revising the paper and agree to be accountable for all aspects of the work.

\section{Disclosure}

The authors report no conflicts of interest in this work.

\section{References}

1. McLin WM, de Boer HM. Public perceptions about epilepsy. Epilepsia. 1995;36:957-959.

2. Berhanu S, Alemu S, Asmera J, Prevett M. Primary care treatment of epilepsy in rural Ethiopia. Ethiop J Health Dev. 2002;16(3):100-103.

3. Robb P. A Manual for Health Workers. Bethesda: U.S, Department of Health and Human Services; 1981. [Epilepsy].

4. Browne R. Hand Book of Epilepsy. LippinCott-Raven, Philadelphia; 8 International journal of collaborative research on internal medicine and public health. November 2010;2(11):361-376.

5. Danesi MA. Patient perspectives on epilepsy in developing country. Epilepsia. 1884;25(2):184-190.

6. Nyame PK, Biritwum RB. Epilepsy: knowledge, attitude and practice in literate urban population, Accra, Ghana. West Afr J Med. 1997;16(3): 139-145.

7. Chilopora GC, Kayange NM, Nyirenda M. Attitudes to epilepsy in Malawi. Malawi Med J. 2001;17(4):139-145.

8. Shaba B, McLachlan M, Carr SC, Ager A. Palliative versus curative benefits regarding tropical. Epilepsia. 1884;25(2):184-190.

9. Chilopora GC, Kayaange NM, M Nyirenda M, Newman PK. Epilepsy as traditional and medical attributions. Cent Afr J Med. 1993;39(8): 165-167.

10. Caveness WF, Gallup GH Jr. A survey of public attitudes toward epilepsy in 1979 with an indication of trends over the past thirty years. Epilepsy. 1980;21:509-518.

11. Alem A, Jacobsson L, Araya M, Kebede D, Kullgren G. How are mental disorders seen and where is help sought in rural Ethiopian community? Acta Psychiatrica Scand. 1999;399:100.

12. Mesfin D. Knowledge, Attitude and Practice of Seboka Boshe Peasants Association towards Epilepsy. Ethiopia: Jimma University; 1997.

13. Kabir M, Iliyasu Z, Abubakar IS, Kabir ZS, Farinyaro AU. Knowledge, attitude and beliefs about epilepsy in northern Nigeria. Ann Afr Med. 2005;4(3):107-112. 
14. Gedefa M, Wolde T, Solomon G. Knowledge, attitudes and practices with respect to epilepsy among preparatory school students in Mekelle city, Ethiopia. Int J Collab Res Int Med Public Health. 2012;4(3): 203-215.

15. Shafiq M, Tanwir M, Tariq A, et al. Public knowledge and attitude in a slum area of Karachi, Pakistan. Eur J Eplepsy. 2007;16(4):330-337.

16. Tekle-Haimanot R, Abebe M, Forsgren L, et al. Attitude of rural people in central Ethiopia towards epilepsy. Soc Sci Med. 1991;32:203-209.

17. Mecarelli O, Capovilla G, Romeo A, Rubboli G, Tinuper P, Beghi E. Past and present public knowledge and attitudes toward epilepsy in Italy. Epilepsy Behav. 2010;18:110-115.

18. Njamnshi AK, Angwafor SA, Tabah EN, Jallon P, Munaa WFT. General public knowledge, attitudes, and practices with respect to epilepsy in the Batibo Health District, Cameroon. Epilepsy Behav. 2009;14: 83-88.

19. Njamnshi AK, Yepnjio FN, Bissek AC, et al. A survey of public knowledge, attitudes, and practices with respect to epilepsy in Badissa Village, Centre Region of Cameroon. Epilepsy Behav. 2009;16:254-259.

20. Bagic A, Bagic D, Zivkovic I. First population study of the general public awareness and perception of epilepsy in Croatia. Epilepsy Behav. 2009; $15: 170-178$

21. Yoo JK, Jung KY, Park KW, et al. Familiarity with, understanding of, and attitudes toward epilepsy among people with epilepsy and healthy controls in South Korea. Epilepsy Behav. 2009;16:260-267.

22. Shehataa GA, Mahranb DG. Knowledge, attitude and practice with respect to epilepsy among school teachers in Assiut city, Egypt. Epilepsy Res. 2010;92:191-200.

23. Dantas FG, Cariri GA, Cariri GA, Filho AR. Knowledge and attitudes toward epilepsy among primary, secondary and tertiary level teachers. Arq Neuropsiquiatr. 2001;59:712-716.
24. Shehataa GA, Mahranb DG. Knowledge and attitude of epilepsy among secondary schools students (epileptic and nonepileptic) in Assiut city, Egypt. Epilepsy Res. 2011;95:130-135.

25. Njamnshi AK, Tabah EN, Bissek AZ, Yepnjio FN. Knowledge, attitudes and practices with respect to epilepsy among student nurses and laboratory assistants in the South West Region of Cameroon. Epilepsy Behav. 2010;17:381-388.

26. Njamnshi AK, Tabah EN, Bissek AC, et al. Knowledge, attitudes and practice with respect to epilepsy among secondary school students in the Kumbo West Health District - North West Region-Cameroon. Epilepsy Behav. 2010;18:247-253.

27. Panda SB, Prabhu K, Rao S, et al. Evaluation of knowledge of and attitudes toward epilepsy among the health science students of Manipal University. Epilepsy Behav. 2011;20:447-449.

28. Youssef FF, Dial S, Jaggernauth N, et al. Knowledge of, attitudes toward, and perceptions of epilepsy among college students in Trinidad and Tobago. Epilepsy Behav. 2009;15:160-165.

29. Tuan NA, Cuong LE, Allebeck P, Chuc NTK, Tomson T. Knowledge, attitudes and practice toward epilepsy among adults in BaVi, Vietnam. J Epilepsy. 2007;48(10):1914-1919.

30. Kassie GM, Kebede TM, Duguma BK. Knowledge, attitude, and practice of epileptic patients towards their illness and treatment in Jimma University specialized hospital, southwest Ethiopia. N Am J Med Sci. 2014; 6(8):383-390

31. Hashmi SJ, Dixit JV. Knowledge, attitude and practice of epilepsy among patients and family members attending urban health and training center. Global J Med Public Health. 2012;1:5.
Neuropsychiatric Disease and Treatment

\section{Publish your work in this journal}

Neuropsychiatric Disease and Treatment is an international, peerreviewed journal of clinical therapeutics and pharmacology focusing on concise rapid reporting of clinical or pre-clinical studies on a range of neuropsychiatric and neurological disorders. This journal is indexed on PubMed Central, the 'PsycINFO' database and CAS,

\section{Dovepress}

and is the official journal of The International Neuropsychiatric Association (INA). The manuscript management system is completely online and includes a very quick and fair peer-review system, which is all easy to use. Visit http://www.dovepress.com/testimonials.php to read real quotes from published authors. 